\title{
Medical education and coronavirus disease-19: Current experiences and upcoming challenges to be addressed
}

\author{
Carlos de la Cruz-de la Cruz* \\ School of Medicine and University Hospital "Dr. José Eleuterio González”, Universidad Autónoma de Nuevo Leon, Monterrey, Nuevo Leon, Mexico
}

Many of us agree that clinical immersion experiences are fundamental in training every health professional. However, with the high demand in health care-related degrees and programs, educational institutions must address the challenges of modifying their teaching methodology to current needs to achieve the necessary clinical experience each student needs when doing clerkships $^{1}$. In recent years, medical schools have developed different methods to facilitate student learning by reducing or eliminating seminars and lectures, promoting the use of apps for teaching basic science-related subjects, advocating collaborative work among students, and using different resources for diverse types of learning ${ }^{2,3}$.

After the outbreak of coronavirus disease 2019 (COVID-19) and the need for social distancing as a preventive measure for containing its spread, medical education has been interrupted and the need for complete migration to digital platforms has been subsequently discovered. In addition to this, medical schools and hospitals have suspended clinical rotations for undergraduates as a part of a strategy to flatten the curve by decreasing the risk of exposure and avoiding undesirable health outcomes in their students. This has raised academic concerns in those who are currently rotating through different medical specialties due to the potential reduced clinical exposure ${ }^{4}$, especially senior students in internship (one of the most important and unique opportunities for the development of crucial clinical skills). Therefore, medical schools are expected to ensure that students achieve desirable medical competences and graduation requirements.

Medical education institutions have responded to this challenge by transitioning from the workplace or medical school setting to a distance education methodology using information and communication technologies ${ }^{4}$. Our school has implemented a digital strategy to transform presential teaching-learning processes to an online methodology with the help of an official Moodle e-learning platform, Microsoft Teams, and ExamSoft software. To our advantage, many students have already been exposed to these digital technologies, allowing the migration process (hopefully temporary and brief) to be fluid and operative. Our institution has had experience in providing these platforms to students for access to in-house and publicly available digital content, discussion forums between students and facilitators, and submission of assignments. After the COVID-19 pandemic, these strategies have become harmoniously extended in our school. For example, many faculty members have shifted to live online conferences and webinars using Microsoft Teams to encourage academic discussion. This has got to a point where professors have helped students experience live or real-world clinical environments through virtual shifts (standardized clinical problems resolved in teams during regular shift hours) and prerecorded or real-time

\section{Correspondence:}

${ }^{*}$ Carlos de la Cruz-de la Cruz E-mail: cadelacruz97@gmail.com
Date of reception: 24-04-2020

Date of acceptance: 14-07-2020 DOI: 10.24875/RMU.20000042
Available online: $30-10-2020$ Medicina Universitaria. 2020;22(3):138-139 www.medicinauniversitaria.org

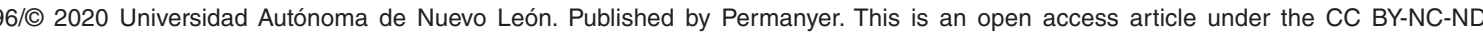
license (http://creativecommons.org/licenses/by-nc-nd/4.0/). 
surgeries, and in-house or online routine video appointments discussed between students and professors.

Another topic that worries many is student evaluations. For some time, our school has adopted ExamSoft assessment software to replace traditional paper-based examinations, with enormous advantages and benefits for both professors and examination takers (e.g., reducing potential cheating, recovery of student's work in case of malfunction, immediate scoring, and feedback on student's performance). This has allowed the transfer to remote testing; however, there have been disadvantages, such as other academic dishonesty techniques, technology availability, connection speed, screen size, and resolution.

Many other countries have adopted similar remote educational approaches ${ }^{2,4-6}$. It is expected that these digital strategies adopted by our institution will help students achieve the required minimal medical professional competences and skills, at least temporarily, although there are many challenges that we will need to address (Table 1). Nevertheless, the most important concern caused by the uncertainty of the duration and consequences of this pandemic is student roles in patient care. Student-patient interactions have a critical role during medical training for developing professional attitudes, skills, and reasoning, as well as cultural sensitivity ${ }^{7}$. Although designing other teaching methods that can be accessed remotely through official institutional platforms, such as virtual clinical simulations, online discussion of clinical cases, clinical role play, recorded video scenarios, and objective structured clinical examinations, may be a useful option for substituting real patient encounters, they should be strategically combined with clinical training with physical contact to incorporate some essential interpersonal skills (verbal and non-verbal communication, empathy, teamwork, and stress management) for experience-based learning $^{8}$, which would not be addressed well enough through digital strategies like ours. Sir William Osler once stated: "For the junior student in medicine and surgery, it is a safe rule to have no teaching without a patient for a text, and the best teaching is that taught by the patient himself" ${ }^{\prime}$. Taking the aforementioned in mind, it will be best for schools to establish actions in the best interest of their students and institutional beliefs. Let us be open-minded since this enduring
Table 1. Challenges to be addressed in online educational settings

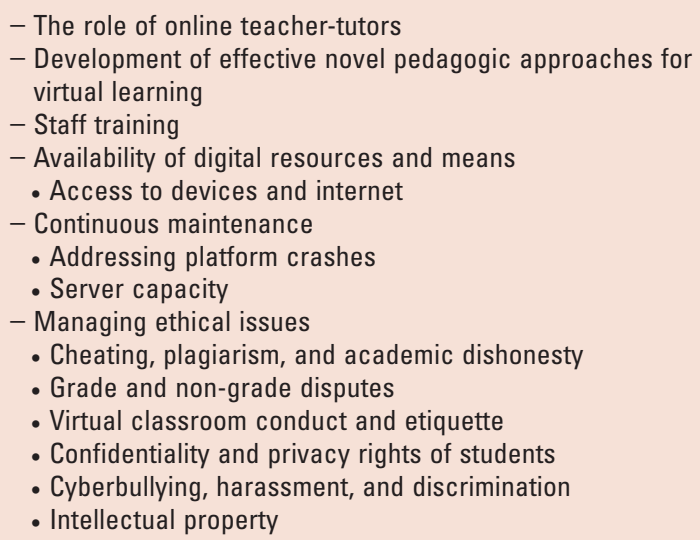

transformation for medicine may have positive profound effects on the future of medical programs and telemedicine.

Unfortunately, severe acute respiratory syndrome coronavirus 2 is not disappearing anytime soon. We must learn to cope with COVID-19 as we wait for effective treatment options and a widespread vaccine; however, a student's dream must not be kept on standby.

\section{Conflicts of interest}

The author declares that there are no conflicts of interest.

\section{References}

1. Hemmer P, Ibrahim T, Durning SJ. The impact of increasing medical school class size on clinical clerkships: a national survey of internal medicine clerkship directors. Acad Med. 2008;83:432-7.

2. Rose S. Medical student education in the time of COVID-19. JAMA. 2020;323:2131-2.

3. Skochelak SE, Stack SJ. Creating the medical schools of the future. Acad Med. 2017;92:16-9.

4. Ferrel MN, Ryan JJ. The impact of COVID-19 on medical education. Cureus. 2020;12:e7492.

5. Mian A, Khan S. Medical education during pandemics: a UK perspective. BMC Med. 2020;18:100.

6. Sánchez S, Ariza A. Educación quirúrgica en Colombia en la era de COVID-19. Rev Colomb Cir. 2020;35:250-5.

7. Spencer J. Patients in medical education. Lancet. 2004;363:312-9.

8. Ahsen NR, Batul SA, Ahmed AN, Imam SZ, Iqbal H, Shamshair K, et al. Developing counseling skills through pre-recorded videos and role play: a pre-and post-intervention study in a Pakistani medical school. BMC Med Educ. 2010;10:7.

9. Osler W. The hospital as a college. In: Aequanimatus, and Other Addresses. Ch. 16. London: HK Lewis; 1905. 